\title{
QUANTIFYING SIZE AND SHAPE DIFFERENCES BETWEEN MUTURU AND N'DAMA BREEDS OF CATTLE
}

\author{
S.N. IBE AND A.G. EZEKWE \\ Department of Animal Science, University of Nigeria, Nsukka \\ Received 21 July 1993; Accepted 12 April, 1994
}

\begin{abstract}
Body weight and eight linear body traits, namely heart girth, body and diagonal lengths, height at withers and at hip, width of loin and at pelvic bone, and depth at rear flank, were measured forthnightly on 32 Muturu bulls, 16 of which were born in the dry season (Muturu -D) and the remaining 16 in the rainy season (Muturu-R), and on 11 N'dama bulls. Correlations between all pairs of traits in all groups were high, positive and significant ( $r$ $>0.093$ ). The first two principal components derived from the correlation matrix of the linear measurements, PCI and PC2 accounted for at least $98 \%$ of total variance in all cases and were regarded as 'size' and 'shape' vectors, respectively. Whereas $\mathrm{PC1}$ gave largest weight to heart girth, $\mathrm{PC} 2$ gave largest weight to two or more different other linear measurements in the three groups. N'dama laad the best conformation, followed by Muturu $-D$ and then Muturu - R. PC-based prediction models were more parsimonius than linear measure-based models and are considered preferable for selecting animals for "optimal" balance. Also, in aldition to discriminating between the two different breeds, PC- based discriminant functions were able to discriminate among individuals within the same breed on the basis of nutritional differences. These functions are therefore recommended for classifying animals according to different macro and micro criteria.
\end{abstract}

Key Words: Body size, shape, linear measurement, parsimonious component, discriminant function

\section{INTRODUCTION}

Body size and shape (or conformation) are important traits in meat animals. Whereas the former has been largely estimated quantitatively by scale weights, the later has generally been described by visual appraisal, giving rise to subjective scores and such descriptions as blocky, rangey, compact, ctc. However, various linear body traits have traditionally been assessed and recorded in many countries (Zarnecki et al., 1985), and their rclationships with body size, shape and production have been investigated by previous workers.

For example, Lerner (1937) observed that shank length was a critcrion of body size in broiler chickens, while Jaap and Penquite (1938) reported that the most desirable measure of body shape in chickens was the relationship between the cube root of body weight and length of shank. In cattle, while Wilson et al. (1969) used the product of chest depth, hook width and body length as a measure of mature size, Jeffery and Berg (1972) used weight/heiglit ratios as indicators of cow condition. Also, in studies involving three West African breeds of cattle in Nigeria, Buvanendran et al. (1980) reported that under ficld conditions, live weight estimated using chest girth alone may be preferred to combinatons with other measurements.

More recently, the multivariate techniques of principal components and factor analysis have been found uscful for analyzing data on body wcight and linear body measurements of meat animals to provide quantitative measures of body size and shape (Brown et al., 1973; Carpenter et al., 1978; McCurley and Mclaren, 1981; Zarnecki et al., 1985; Zarnecki et al., 1987; Ibc, 1989). Oucstions of optimal size and shape of beef cattle have gencrated controversy among cattlemen and scientists alike (Carpenter et al., 1978). Moreover, a quantitative measure for animal conformation is desirable as it will enable reliable genetic parameters for this trait to be estimated and permit its inclusion in 
breeding programmes (Ibe, 1989). Also, the relationship between scale weight and easily measured linear body traits will be useful for predicting body weight in situations where weighing facilities are not available, as in many African farming conditions (Mani et al., 1991).

The objectives of this study are, therefore, (i) to examine the nature of interdependencies among different lincar body measurements in two tropical beef breeds of calle, namcly Muturu and N'dama, and their relationships with scalc weight, (ii) w determin sppropriate quantitative measures of body size and conformation (shape) in these breeds, and (iii) to use these quantitative measures to discriminate between them.

\section{MATERIALS AND METHODS}

\section{Material}

Thirly-two Muturu bull calves were used. Sixteen of these born during the dry season between November and January (Muturu-D) had an average weaning age of 40) days (26-62 days); the remaining sixteen born during the rainy season between April and July (Muturu -R) had an average weaning age of 69 days (56-97 days). These calves were purchased from Muturu cattle rearers around the research area, a derived savanna zone. Eleven N'dama bull calves with an average age of 140) days (86-150) days) were purchased from a commercial ranch. All calves were reared in the University Teaching and Rescarch Farm.

Reconstituted powdered milk was fed twice daily (morning and evening) at the rate of $700-800 \mathrm{ml}$ per calf per day to the Muturu calves for a peried of about 40) days. (Calves of both breeds also had daily access to fresh green fodder consisting mainly of guinca grass (Panicum maximum) and giant star grass (Cinodon dactylon). In addition, a $16 \%$ crude protein concentrate ration, comprising maize $(39 \%)$, palm kernel meal $(27 \%)$, undelinted cotton seed cake (4\%), dry brewer's spent grain $(26 \%)$ and bone meal $(2 \%)$, was fed to the calves at the rate of 400-800 g per calf per day, depending on the calf's body weight. This feeding regimen was maintained until the calves were approximately 9 months old when brewer's spent grain was substituted for the $16 \%$ crude protein concentrate rations. Calves were thenceforth maintained only on the spent grain and normal grazing until the termination of the experiment. Routine deworming and spraying programmes of the farm were carried out.

Calves were weighed every forthnight between $07.15 \mathrm{~h}$ and $08.30 \mathrm{~h}$ before morning feeding/grazing. The following linear body mcasurements werc also taken on each animal after weighing: height at withers (HW), heart girth (HG), body length (BL), height at hips (HH), width of loin (WL), width at pelvic bone (WPB), diagonal length (DL) and depth at rear flank (DRF).

\section{Statistical Analysis}

The correlation matrix of body weight (BW) and the linear body measurements were determined in each of the three experimental groups of catle, namely Muturu-D, Muturu-R and N'dama.

A principal components analysis was run on a subset of the overall correlation matrix corresponding to the lincar measurements in each group. The technique, fully described by Anderson (1958), Morrison (1967) and Draper and Smith (1981), involves computation of eigenvectors and eigenvalues of the correlation matrix. Whereas the former are principal component weights, the latter represent the generalized variance explained by each principal component ( $\mathrm{PC}$ ). The $\mathrm{i}-\mathrm{th} \mathrm{PC}$, considering a p-variate system, may be represented, following Ibe (1989), as in (1).

$P C_{i}=a_{j} X_{j}+a_{i 2} X_{2}+\ldots \ldots \ldots \ldots . . .+a_{i p} x_{p} \ldots .$.

where $a_{i j}$ is the $j$-th component of the coefficient vector of the linear transformation, and $\mathrm{X}_{\mathrm{j}}$ is the $\mathrm{j}$-th original variable (lincar body measurement).

The stepwise variable selection multiple regression approach was used to obtain models for predicting live body weight from linear body measurements (2) and from cstablished 
principal components (3).

$$
\begin{aligned}
& \mathrm{BW}=\mathrm{a}+\mathrm{B}_{\mathrm{j}} \mathrm{xi}+\ldots .+B_{\mathrm{k}} \mathrm{x}_{\mathrm{k}} \ldots(2) \\
& \mathrm{BW}=\mathrm{a}+\mathrm{B}_{\mathrm{j}} \mathrm{PCi}+\ldots . .+B_{\mathrm{k}} \mathrm{PC}_{\mathrm{k}} \ldots
\end{aligned}
$$

where $\mathrm{Bw}$ is the body weight, $\mathrm{a}$ is the regression intercept, $B_{i}$ is the $i$-th partial regression coefficient of the $i$ - th linear body measurement, $x_{i}$ or the $i$ - th principal component, $\mathrm{PCi}$.

A simple linear regression model (4) wasi fitted to the PC-age data to determine how eact $\mathrm{PC}$ was changing with age.

$$
\mathrm{PC}_{\mathrm{i}}=\mathrm{a}+B \mathrm{~A}_{\mathrm{i}}
$$

where $a$ is the intercept, $B$ is the regression slope and $A_{i}$ is the $i-t h$ age. Correlations between the principal components and betwoen each of them and the linear body iratis were also determincei.

Discriminant analyses, using the inear body measurements and established PCs, were performed. This technique determines $k-1$ new orthogonal variables, $D_{i}$ originating from the measured traits by linear transformaton (Hyankova et al., 1985). It was used here to discriminate among the three groups of animals. The $\mathrm{i}$-th discrminant function is of the form in (5).

$$
\mathrm{D}_{\mathrm{i}}=\mathrm{dilzl}+\mathrm{di} 2 \mathrm{z}_{2}+\ldots \ldots .+\mathrm{d}_{\mathrm{ij}} \mathrm{z}_{\mathrm{j}} \ldots . .
$$

where $\mathrm{z}_{\mathrm{j}} \mathrm{s}$ are standardized values of the original variables and dij 's are the standardized classification function coefficients.

All analyses were done using the Statgraphics Statistical Graphics System Software for personal computers (STSC, 1987).

\section{RESULTS}

\section{Correlations}

Correlations between BW and each of the linear body traits and between the latter themselves in all groups were high, positive and significant $(\mathrm{r}>0.93) ; \mathrm{P}<.001)$. In all groups, while correlations between the first derived principal component, PC1 and BW and between the former and each of the linear body measurements were high, positive and significant (average $r>0.96 ; P<.001$ ), those between the second principal component, $\mathrm{PC} 2$ and the aforementioned traits were high, negative and significant (average $r=-0.96 ; \mathrm{P}<.001$ ). Also, a high, negative and significant correlation $(r=$ -0.999 to $-0.952 ; \mathrm{P}<.001)$ between $\mathrm{PC1}$ and $\mathrm{PC} 2$ in all groups was obtained.

\section{Principal Components}

Principal component weights derived from the correlation matrix of the eight linear body measurements in the three groups studics are given in Table 1 . In all cases, the first two components, PCl and PC2 acconnco for a* least $98 \%$ of toual variance. As a resul, or: these two components were consterci. Th. first $P C$ consists of all positive coefficients ant regarded as the 'size' vector, whe pes pe, consisting of both positive an nearia: coefficients, is the 'shape' vector (Bitines a tal. 1973; Carpenter et al., 1978; Mccumby and McLaren, 1981; Zarrnecki et al., 1985; Zarncki et al., 1987; the, 1989). In all groups, the largest coefficient in PC1 was for $\mathrm{HG}$, followed by $\mathrm{DL}$ and $\mathrm{BL}$, in that order. In Muturu-D, PC2 essentially contrasts individuals with small heart girth and shallowness at rear flank with those having pronounced back and diagonal lengths and height at withers and at hips. In N'dama, the contrast is between individuals having pronounced height at withers and at hips and those poor in the other linear body measurements.

\section{Linear prediction models}

Models for predicting body weight from linear body measurements and from the established principal components are given in Tables 2 and 3, respectively. Whereas five of the eight linear body traits, namely $\mathrm{HG}, \mathrm{WL}$, WPB, DL and DRF, explained over $98 \%$ of the variation in body weight in Muturu $-D$, only four (HG, WL, HH and BL) and three (HW, WL and WPB) expalined same amount of variation in body weight in Muturu-D, only four ( $\mathrm{HG}$, WL, $\mathrm{HH}$ and BL) and three (HW, WL and WPB) explained same amount of variation in Muturu - R and N'dama, respectively. All regressions were significant $(P<.001)$. With the 
exception of WL which appeared in prediction models for the three groups, HG in models for the two Muturu groups, and WPB in models for Muturu-D and N'dama, the models used different linear measurements to predict body weight.

Both $\mathrm{PCI}$ anc $\mathrm{PC} 2$ were required to predict BW in Muturu-D, whereas only $\mathrm{PCI}$ was required in Muturu- $R$ and in N'dama. Each principal component model accounted for about $97 \%$ of the total variation and was significant $(\mathrm{P}<.001)$.

\section{Change of body size and shape indices with age}

Regressions of $\mathrm{PCI}$ and $\mathrm{PC} 2$ individually on age for all groups are presented in Tables 4 and 5 , respectively. Table 4 shows that, although N'dama had the largest body size index at birth and at subsequent ages compared with two Muturu groups, the positive rate of change in the index with age was not statistically different $(\mathrm{P}>.05)$ among the threc (average $=7.29)$. On the other hand, the rate of change in shape index was negative, with $\mathrm{N}^{\prime}$ dama showing the smailest change (0.68) compared with 3.99 and 4.53 for Muturu-D and Muturu-R respectively.

At the ages considered, N'dama had the best conformation, followed by Muturu-D and then Muturu-R. Ibe (1989) had reported that larger PC2 values were indicative of better conformation. Each of the linear regression models accounted for between 80 and $97 \%$ of total variation and was significant $(\mathrm{P}<.001)$.

\section{Discriminant analysis}

Results of the discriminant analyses using both linear body measurements and derived principal components are presented in Table 6 . The discriminant function derived from the lincar measurements provides good discrimination betwecn N'dama and the two Muturu groups but could not discriminate between the latter (see group centroids in Table 6). The function correctly classified $65.6,67.7$ and $98.9 \%$ of N'dama, Muturu-D and Muturu-R individuals, respectively.
On the other hand, the function derived from the two principal components provides good discrimination among the three groups (See group centroids in Table 6). More importantly, the PC-based discriminant function provided 99.4 to $100 \%$ correct classification of individuals belonging to the three groups.

\section{DISCUSSION}

The high correlations between body weight and all the linear body measurements indicate a definite association of the latter with body growth. Similar high correlations have been reported in temperate breeds of cattle by Jeffery and Berg (1972) and by Carpenter et al. (1978), and in three West African breeds, namely White Fulani, Sokoto Gudali and N'dama, by Buvanendran et al. (1980). As a result of such high correlations, it is possible to predict growth of the whole body from parts thereof. This is useful in farm situations where scales are not available, as indicated carlier. Even where scales are available, it is recognised that scale weight does not adequately distinguish difference in body composition of animals and is greatly influenced by fluctuations in gut fill (Carpenter et al., 1978; Ibe, 1989). Dalton (1981) estimates that $10-25 \%$ of actual weight in cattle and sheep could be accounted for by gut fill. Fitzhugh $e t$ al. (1967) also observed that while weights of mature cows vary considerably during the production cycle, depending on seasonal changes in nutrient sources and physiological status, especilly pregnancy and lactation, linear body measurements of these animals vary little throughout the production cycle.

However, due to obscrved multicollinearity (indicated by high pairwise correlations of the predictor variables and small eigenvalue of the correlation matrix), use of these linear measures to predict body weight/growth is considered statistically unsound as unstable estimates may results (Ibe, 1989), Icading to unreliable predictions. Gill (1986) also stated that least squares estimates of parameters are known to be highly erratic if two or more $\mathrm{X}$-variables are related in such a way that multicollinearity 
causes near-singularity of the X'Xmatrix. These observations justify the use of indices of the linear measurements, referred to as principal components, for prediction, since they are orthogonal to each other.

Over $98 \%$ of total variation in the system of the eight linear body measures was explained by general body size differences, represented by PCI. This probably accounts for the high positive correlation among all body parts and between PCI and body weight. Carpenter et al. (1978) reported a high correlation of 0.93 between cow weight and PCI from their data and observed that the first two principal components contained $90 \%$ of the information provided by their original four variables. On the other hand, less than $2 \%$ of total variance was explained by shape differences, represented by PC2, Body shapes do not always indicate a positive relationship among linear body measures, hence their negative correlations with PC2. Also, the high negative correlation between body size and shape indices (PCI and PC2, respectively) indicates that the two are different and that body shape or conformation decreases with increasing body size. Increase in the body size of an animal could be due to excessive fat deposition in different parts of the body which could result in poor body shape. Brown et al (1973) recognized the importance of "optimal" balance in cattle, since those which represent real extremes in some body measures may be less desirable from the standpoint of fitness. They also stated that since body weight, size or shape may be reached in different ways by animals, selection for a given performance trait need not be accompanied by an increased uniformity in body shape.

Results indicate that body size was influenced most by heart girth, irrespective of breed and season of birth. Zarnecki et al. (1987) similarly reported that the size vector, PC1 derived from their data gave the largest weight to heart girth for 12 and 18 month old heifers and 12-month old bulls. The implication is that a breeder or cattleman could have fairly good idea of body sizes of his animals by simply measuring their heart girths. Thys and Hardouin (1991) recognized heart girth as the most precise and easy to apply of the linear body measurements for predicting body weight in sheep. Their prediction models with heart girth only explained 86.5 and $90.8 \%$ of total variation of body weight in rams and ewes, respectively. Buvanendran et al. (1980) observed that chest girth accounted for $86-96 \%$ of total variation in body weight in three West African breeds of cattle, and therefore recommended the use of this body measurement alone to predict live-weight under field conditions.

For body shape, body and diagonal lengths contributed most in Muturu-D, whercas in Muturu-R, in addition to these length measurements, heights at withers and at hips were important. In N'dama, the most important measures contributing to shape are heights at withers and at hips. These results confirm the observation by Brown et al. (1973) that body shape may be reached in different ways and indicate that shape of animals is not as easy to quantify as body size. Different linear body measures may be required to do this in different breeds and under different circumstances, for example, feeding.

Although both linear measure-based and PC-based models for predicting body weight differed with breed and with seasonal- changes within breed, the latter were more parsimonious and are considered preferable for purposes of selection for "optimal" balance, since they combine both body size and shape components into a composite index for prediction. The better conformation of Muturu bulls born during the dry season compared with those born during the rainy season when feed was more abundant indicates that feed restriction, as occurs during the dry season, may improve the shape of animals, although it adversely affects body size. This is in consonance with the result that body size and body shape are highly negatively correlated. A similar effect of feeding restriction has been reported in broilers by Ibe (1990)

Discriminant functions derived from both linear measurements and principal components 
confirm that the two breeds, Muturu and N'dama are different, as expected. However, the PC-based function was able to detect differences due to non-animal factors, such as nutrition among individuals of the same breed. PC-based functions are therefore expected to provide more precise discrimination among groups, thereby facilitating better classification of individuals according to different macro and micro criteria, such as breed, strain, variety, health status, nutrient status, et cetera.

\section{REFERENCES}

ANDERSON, T.W. (1958.) Introduction to Multivariate Statistical Analysis. John Wiley and Sons, Inc., New York

BROWN, J.E. BROWN, C.J. and BUTTS, W.T. (1973.) Evaluating relationships among immature measures of size, shape and performance on beef bulls 1. Principal components as measures of size and shape in young Hereford and Angus bulls. J. Anim. Sci. 36:1010-1020

BUVANENDRAN, V., UMOH, J.E. and ABUBAKAR, B.Y. (1980.) An evaluation of body size as related to weight of three West African breeds of cattle in Nigeria. J. Agric, Sci., Camb. 95: 219-224

CARPENTER, J.A. FITZBURGH, T.C., CARTWRIGHT, T.C. THOMAS, R.C. and MELTON, A.A. (1978.) Principal components for cow size and shape. J. Anim. Sci. 46; 370-375

DALTON, C. (1981.) An Introduction to Practical Animal Breeding. The English Language Book Society and Granada, London.

DRAPER, N. and SMITH, H. (1981.) Applied Regression Analysis. John Wiley and Sons, Inc. New York.

FITZHUGH, H.A. Jr., CARTWRIGHT, T.C. and TEMPLE, R.S. (1967.) Genetic and environmental factors affecting weight of beef cows. J. Anim. Sci. 26:991-1001

GILL, J.L. (1986.) Outliers, residuals, and influence in multiple regression. J. Anim. Breedg. Genet. 103:161-175

HYANKOVA, L. KNIZE, B., HYANEK, J. and SILER, R. (1985.) Discriminant analysis of highly inbred lines and hybrid combinations of fowl on the basis of osteometric traits. Z. Tierzuchtg. Zuchtgsbiol. 102:230-237
IBE, S.N. (1989.) Measures of size and conformation in commercial broilers. J. Anim. Breed. Genet. 106:461-469.

IBE, S.N. (1990.) Effect of feed restriction on principal component measures of body and conformation in commercial broiler chickens. Nig. J. of Anim. Prod. 17:1-5

JAAP, R.G. and PENQUITE, R. (1938.) Criteria of conformation in market poultry. Poultry Sci. 17:425-430.

JEFFERY, H.B. and BERG, R.T. (1972.) An evaluation of several measurements of beef cow size as related to progeny performance. Can. J. Anim. Sci. 52:23-37

LERNER, I.M. (1937.) Relative growth and hereditary size limitation in the domestic fowl. Hilgardia 10: 511-560

MANI, R.I. ABDULLAHI, A.R. and VON KAUFMANN, R. (1991.) Comparison of scale weights to tape estimates and their rclationships with condition scores in Bunaji cattle. Nig. J. of Anim. Prod. 18:78-81.

McCURLEY, J.R. AndMcLAREN, J.B. (1981.) Relationship of body measurements, weight, age and fatness to size and performance in beef cattle. J. Anim. Sci. 52: 493-499

MORRISON, D.F. (1967.) Multivariate Statistical Methods. McGraw- Hill Book Co., New York.

STSC. (1987.) Statgraphics. Statistical Graphics System Software STSC. Inc., U.S.A.

THYS, E. and HARDOUIN, J. (1991.) Prediction of sheep body weight in markets in the far North Cameroon. Livestock Res. for Rural Dev. 3:74-78

WILSON, L.L. GILLOOLY, J.E. RUGH, M.C. THOMPSON, C.E. and PURDY, H.R. (1969.) Effects of energy intake, cow body size and calf sex on composition and yield of milk by Angus-Holstein cows and preweaning growth rate of progeny. J. Anim. Sci. 28: 789-795

ZARNECKI, A., FIMLAND, E and RONNINGEN, K. (1985.) Conformational traits and their relation to production in Norwegian Red Cattle. Z. Tierzuchtg. Zuchtgsbiol. 102:271-284.

ZARNECKI, A., RONNINGEN, $K$. and STOLZMAN, M. (1987.) Multivariate statistical methods for quantifying size and shape differences between F1 crosses of different Friesian strains. $Z$ Tierzuchtg. Zuchtgsbiol. 104:28-34. 
Table 1 PRINCIPAL COMPONENT WEIGHTS FOR THE VARIOUS LINEAR BODY MEASUREMENTS

\begin{tabular}{llllllr} 
& \multicolumn{2}{c}{ Muturu-D $^{\mathbf{a}}$} & \multicolumn{2}{c}{ Muturu-R } & \multicolumn{2}{c}{ N'dama $^{\text {PC2 }}$} \\
Measuremeni $^{b}$ & PC1 & PC2 & PC1 & PC2 & PC1 & PC2 \\
\hline HW & .294 & .078 & .300 & .331 & .315 & .650 \\
HG & .571 & -.429 & .584 & -.670 & .582 & -.211 \\
HH & .306 & .082 & .302 & .334 & .313 & .591 \\
WL & .108 & -.118 & .133 & -.126 & .141 & -.194 \\
WPB & .198 & -.286 & .221 & -.053 & .206 & -.238 \\
BL & .422 & .516 & .397 & .317 & .396 & -.181 \\
DL & .432 & .436 & .410 & .394 & .404 & -.200 \\
DRF & .279 & -.501 & .293 & -.234 & .287 & -.130 \\
Cum.\%of total & & & & & & 98.43 \\
Variance & 98.50 & 99.13 & 98.69 & 99.12 & 97.60 & \\
\hline
\end{tabular}

a $\quad$ PC1 $=$ first principal component; $\mathrm{PC2}=$ second principal component

b. $\quad H W=$ height at withers; $H G=$ heart girth; $H H=$ height at hips $W L=$ width of loin; $\mathrm{WPB}=$ width at pelvic bone; $\mathrm{BL}$-body length; $\mathrm{DL}=$ diagonal length; $\mathrm{DRF}=$ depth at rear flank.

Table 2. MODELS FOR PREDICTING BODY WEIGHT FROM LINEAR BODY MEASUREMENTS

\begin{tabular}{|c|c|c|c|c|}
\hline Group & & Model $^{\mathbf{a}}$ & $\mathbf{R}^{2}(\%)$ & S.E. \\
\hline Muturu-D & $\mathrm{BW}=$ & $\begin{array}{l}-94.46+1.13 \mathrm{HG}+1.41 \mathrm{WL} \\
+1.10 \mathrm{WPB}+1.09 \mathrm{DRF}- \\
0.58 \mathrm{DL}\end{array}$ & 98.3 & 4,360 \\
\hline Muturu-R & $\mathbf{B W}=$ & $\begin{array}{l}-87.27+1.08 \mathrm{HG}-0.81 \mathrm{HH} \\
+3.08 \mathrm{WL}+0.81 \mathrm{BL}\end{array}$ & 98.2 & 4.666 \\
\hline N'dama & $\mathrm{BW}=$ & $\begin{array}{l}-255.66+2.25 \mathrm{HW}+4.52 \mathrm{WL} \\
+1.84 \mathrm{WPB}\end{array}$ & 98.3 & 5.779 \\
\hline
\end{tabular}

a See Table 1 for meanings of trait abbreviations

Table 3 MODELS FOR PREDICTING BODY WEIGHT FROM PRINCIPAL COMPONENTS

\begin{tabular}{|c|c|c|c|}
\hline Group & Model $^{\mathbf{a}}$ & $\mathbf{R}^{2}(\%)$ & S.E. \\
\hline Muturu-D & $\begin{array}{c}\mathrm{BW}=-\frac{138.22+2.18 \mathrm{PC} 1+}{2.00 \mathrm{PC} 2}\end{array}$ & 97.2 & 5.541 \\
\hline Muturu-R & $\mathrm{BW}=-134.08+1.12 \mathrm{PC1}$ & 96.8 & 6.193 \\
\hline N'dama & $B W=-264.65+1.73 P C 1$ & 97.0 & 7.617 \\
\hline
\end{tabular}

$\mathrm{a} \mathrm{BW}=$ body weight; $\mathrm{PC} 1$ and $\mathrm{PC2}=$ ist and 2 nd principal component, respectively. 
Table 4 REGRESSION OF FIRST PRiNCIPAL COMPONENT (PC1) ON AGE

\begin{tabular}{llll}
\hline Group & \multicolumn{1}{c}{ Model } & $\mathbf{R}^{2}(\%)$ & S.E. \\
\hline Muturu-D & PC1 $=115.81+7.16$ Age & 95.7 & 6.276 \\
Muturu-R & PC1 $=118.36+7.47$ Age & 96.9 & 5.401 \\
N'dama & PC1 $=143.98+7.25$ Age & 94.0 & 6.118 \\
\hline
\end{tabular}

TABLE 5 REGRESSION OF SECOND PRINCIPAL COMPONENT (PC2) ON AGE

\begin{tabular}{llll}
\hline Group & \multicolumn{1}{c}{ Model } & $\mathbf{R}^{2}(\%)$ & S.E. \\
\hline Muturu-D & $\mathrm{PC}=-57.29-3.99$ Age & 94.8 & 3.877 \\
Muturu-R & $\mathrm{PC} 2=-67.11-4.53$ Age & 96.6 & 3.399 \\
N'dama & $\mathrm{PC} 2=-13.14-0.68$ Age & 80.5 & 1.117 \\
\hline
\end{tabular}

TABLE 6 FIRST DISCRIMINANT FUNCTION, USING UNEAR BODY MEASUREMENTS AND PRINCIPAL COMPONENTS

\begin{tabular}{|c|c|c|c|c|c|c|c|c|}
\hline \multirow{2}{*}{\multicolumn{2}{|c|}{ Function $^{\mathrm{a}}$}} & \multirow[b]{2}{*}{ Rel. \% } & \multicolumn{3}{|c|}{$\begin{array}{l}\text { Groups } \\
\text { Centroids }\end{array}$} & \multicolumn{3}{|c|}{$\begin{array}{l}\text { \%Correct } \\
\text { Classification }\end{array}$} \\
\hline & & & 1 & 2 & 3 & 1 & 2 & 3 \\
\hline $\mathrm{D}_{1}=$ & $\begin{array}{l}-2.51 \mathrm{HW}+1.56 \mathrm{HG} \\
-3.02 \mathrm{HH}-0.14 \mathrm{WL} \\
-0.02 \mathrm{WPB}+1.99 \mathrm{BL} \\
+1.74 \mathrm{DL}+0.11 \mathrm{DRF}\end{array}$ & 98.23 & 1.36 & 1.01 & -4.19 & 65.6 & 677 & 989 \\
\hline$D_{p}=$ & $+2.82 \mathrm{PCl}+2.92 \mathrm{PC} 2$ & 99.96 & -2.84 & -4.97 & 13.89 & 100.0 & 99.4 & 100.0 \\
\hline
\end{tabular}

a D and D are lst discriminant function based on linear body measurements and on principal components, respectively. See Tables 1 and 3 for meanings of trait abbreviations. 